\title{
Seeding of high temperature air
}

\section{flow}

\section{Journal Article}

\section{Author(s):}

Rusch, D.; Kempe, A.; Rösgen, Thomas

Publication date:

2007

Permanent link:

https://doi.org/10.3929/ethz-b-000006710

Rights / license:

In Copyright - Non-Commercial Use Permitted

Originally published in:

Experiments in Fluids 42(5), https://doi.org/10.1007/s00348-007-0284-4 


\title{
Seeding of high temperature air flow
}

\author{
D. Rusch $\cdot$ A. Kempe $\cdot$ T. Roesgen
}

Received: 7 April 2006/Revised: 21 February 2007/Accepted: 26 February 2007/Published online: 20 March 2007

(C) Springer-Verlag 2007

\begin{abstract}
Seeding of high temperature air flows is problematic because common seeding materials can ignite and may pose a threat for human health in case of inhalation. Sodium chloride is proposed as a seeding material to avoid these problems. The generation of crystals using an ultrasonic atomizer is described and the measured particle size distribution is presented. The described method has the additional advantage that the particle size can easily be adjusted. This allows the operator to comply with the experimental requirements in terms of resolvable frequencies. The described method has been successfully applied to LDA measurements in a $500^{\circ} \mathrm{C}$ air flow.
\end{abstract}

\section{Introduction}

In LDA measurements, particles have to be introduced into the flow in order to have light-scattering objects. The authors faced the specific problem to seed a hot-jet-incrossflow configuration where the maximum temperature is about $500^{\circ} \mathrm{C}$. In addition, the tunnel is open to the environment and a volume flow rate of up to about $1 \mathrm{~m}^{3} / \mathrm{s} \mathrm{had}$ to be continuously seeded for several hours. The description of the experimental setup can be found in Menter et al. (2006). For measurements in air flows, mainly oil droplets produced by atomizers or solid hydrophobic powders, such as metal oxides, are used. For high temperature applica-

D. Rusch · A. Kempe · T. Roesgen $(\bowtie)$

Institute of Fluid Dynamics, ETH Zurich,

8092 Zurich, Switzerland

e-mail: roesgen@ifd.mavt.ethz.ch tions, such as in air flows with temperatures around $500^{\circ} \mathrm{C}$, oil droplets cannot be used since the temperature is higher than both the flash point and the auto-ignition temperature. Thus, such oil droplets would evaporate quickly and even start to burn spontaneously.

The flash point and auto-ignition temperature at ambient pressure for different oils are given in Table 1. The flash point temperature is defined as the minimum temperature at which the vapor pressure of a liquid is sufficient to form an ignitable mixture with air near the surface of the liquid. The auto-ignition temperature in contrast is the minimum temperature required for self-sustained combustion in the absence of an external ignition source.

Metal oxide seeding particles can be used for temperatures up to more than $2,000^{\circ} \mathrm{C}$ according to Albrecht et al. (2003). Since many experiments are performed in open wind tunnel environments, such powders cannot be used for health safety reasons: Roessler et al. (2001) discusses the absorption rate of particles in the human body during breathing. Figure 1 shows the total absorption rate and the absorption rate within the lungs. It can be seen that the total absorption rate for particles with a diameter $>10 \mu \mathrm{m}$ is nearly $100 \%$ but only less than about $10 \%$ reach the lungs as these particles are mainly absorbed in the throat and nose region through sedimentation. Particles with a diameter $<10 \mu \mathrm{m}$, such as typical seeding particles, reach the lungs and are finally absorbed by a diffusion process. The smaller the particles the higher the absorption rate within the lungs. Particles $<0.1 \mu \mathrm{m}$ do not only reach the lungs but can also enter the bloodstream. The total absorption rate shows a minimum at particle diameters of about $0.3 \mu \mathrm{m}$. A large portion of particles of this size are not absorbed but rather exhaled.

Dependent on particle concentration, shape, size and chemical behavior, the human body reacts in different ways 
Table 1 Flash point and auto-ignition temperature for various seeding oils at ambient pressure

\begin{tabular}{lcl}
\hline Oil & Flash point $\left({ }^{\circ} \mathrm{C}\right)$ & Autoignition $\left({ }^{\circ} \mathrm{C}\right)$ \\
\hline Olive oil & 225 & 343 \\
Castor oil & 230 & 449 \\
DOP & $207-218$ & 390 \\
DEHS & 215 & 400 \\
\hline
\end{tabular}

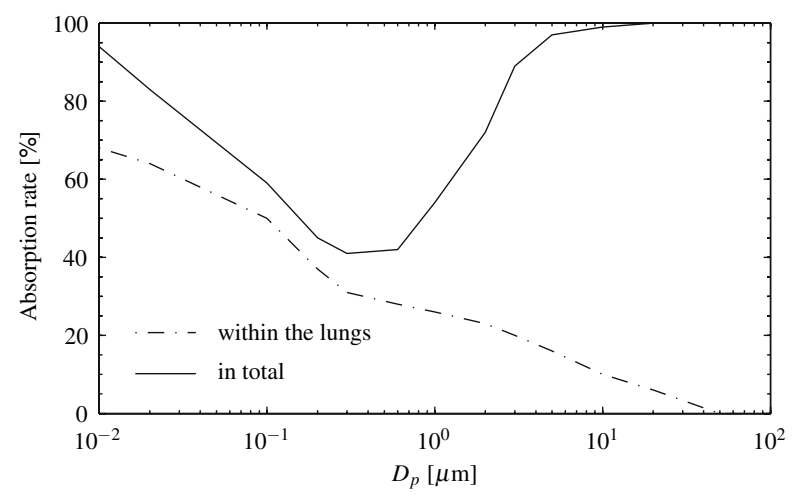

Fig. 1 Absorption rate of aerosol particles in human airway system as given in Roessler et al. (2001)

to those particles: coughing, inflammation, allergic reactions or even cancer can be provoked. In contrast to the hydrophobic metal oxides, sodium chloride $(\mathrm{NaCl}$, "cooking salt") is believed to be even healthy-or at least not dangerous as it is also applied in medical therapies. The effect of inhaling a dry powder of sodium chloride on the airways has been studied by Anderson et al. (1997). In the material safety data sheet for sodium chloride, the concentration in air that will kill $50 \%$ of the test animals (rat) is given to be $>42 \mathrm{~g} / \mathrm{m}^{3}$ for a single exposure of one hour. Such a concentration might be reached only inside the seeding generator. In the experiment, the seeding is injected into the flow and diluted with air. Hence, $\mathrm{NaCl}$ particles are considered to be a suitable seeding material for a hot air flow when there is the possibility for inhalation since the effective concentrations are well below $42 \mathrm{~g} / \mathrm{m}^{3}$. Another advantage is the low material cost and its availability. The use of $\mathrm{NaCl}$ as seeing material is also reported in literature, e.g. by Green and Lane (1964). The temperature range of application is limited by the melting point of $\mathrm{NaCl}\left(801^{\circ} \mathrm{C}\right)$. Above this temperature, sodium chloride emits toxic fumes of chloride and sodium oxide. A possible drawback of $\mathrm{NaCl}$ is its high corrosivity in combination with water. It is hydrophilic and tends to attract the atmospheric water. The chloride is an activator and accelerates corrosion even of stainless steel. Nevertheless, it was successfully applied in the described configuration without significant corrosion as the temperatures were high enough to dry the tunnel after the measurements. The atomizers were cleaned after each usage. The data rates achieved were primarily limited by the amount of seeding air added to the flow and the very low flow velocities. At ambient temperature and velocities of about $1 \mathrm{~m} / \mathrm{s}$, data rates up to $150 \mathrm{~Hz}$ were obtained. At $500^{\circ} \mathrm{C}$ and $3 \mathrm{~m} / \mathrm{s}$, data rates up to $80 \mathrm{~Hz}$ were achieved. Further information regarding the LDA system and the measurements can be found in Rusch (2007).

\section{Generation of sodium chloride crystals}

The salt crystals are produced by an ultrasonic atomizer which is placed in a $\mathrm{NaCl}$ water solution. These atomizers are employed both in medical inhalators and in ordinary humidifiers. The membrane of this device oscillates at an ultrasonic frequency and causes cavitation which in turn leads to the formation of small droplets. The size of these droplets is of the order of $1-10 \mu \mathrm{m}$. As the generated droplets are very small, the water will evaporate quickly and a cube-shaped $\mathrm{NaCl}$ crystal is produced from each droplet. Figure 2 shows the atomizer mounted in a flotation device, which assures a constant water level above the membranes. The fine mesh on top of the atomizer retains splashes.

For continuous seeding, the salt solution is filled into a suitable plastic barrel and the floating atomizer is placed inside. Fittings are attached on the lid in order to supply pressurized air and extract the particle-laden air.

In contrast to commercially available ultrasonic atomizers, which often work with pressurized air (Durst et al.

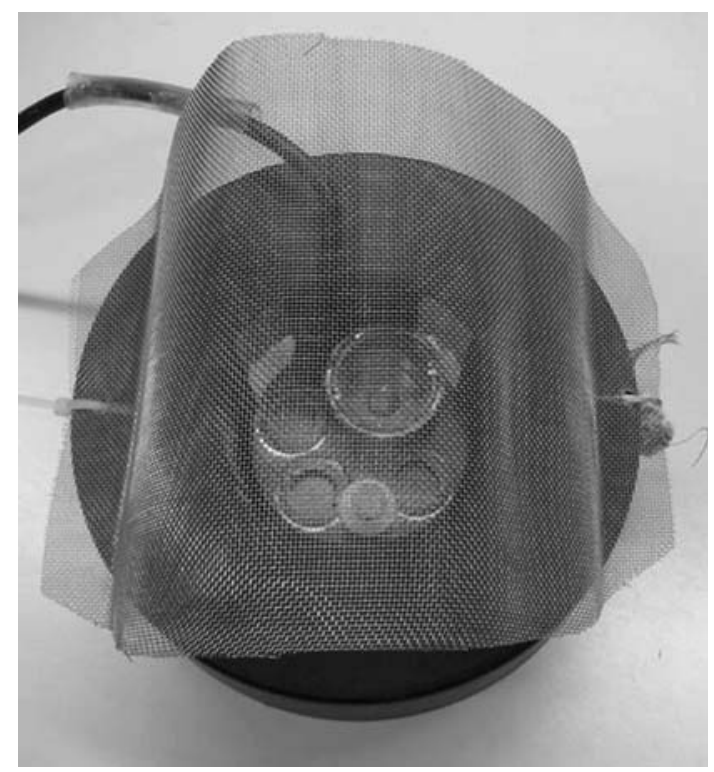

Fig. 2 Ultrasonic atomizer mounted on the floating ring 
1981) and at low volume flow rates, the described device uses an oscillating membrane and just needs some ventilation in order to blow the seeding particles out of the barrel. It can easily be assembled using cheap off-the-shelf products and modified according to the experimental requirements. In addition, the seeding volume flow rate can be controlled using multiple atomizers which can be switched on or off individually and can easily produce higher flow rates. Moreover, the particle size can be controlled as is described in the next section.

\section{Particle size}

\subsection{Theoretical approach}

The $\mathrm{NaCl}$ crystal size can be controlled by the concentration of the solution used, as also reported e.g. by Green and Lane (1964). Applying the mass conservation law for one solution droplet with diameter $D_{s}$ and density $\rho_{s}$, the edge length $L_{c}$ of the sodium chloride crystal cube created by evaporation can be expressed as
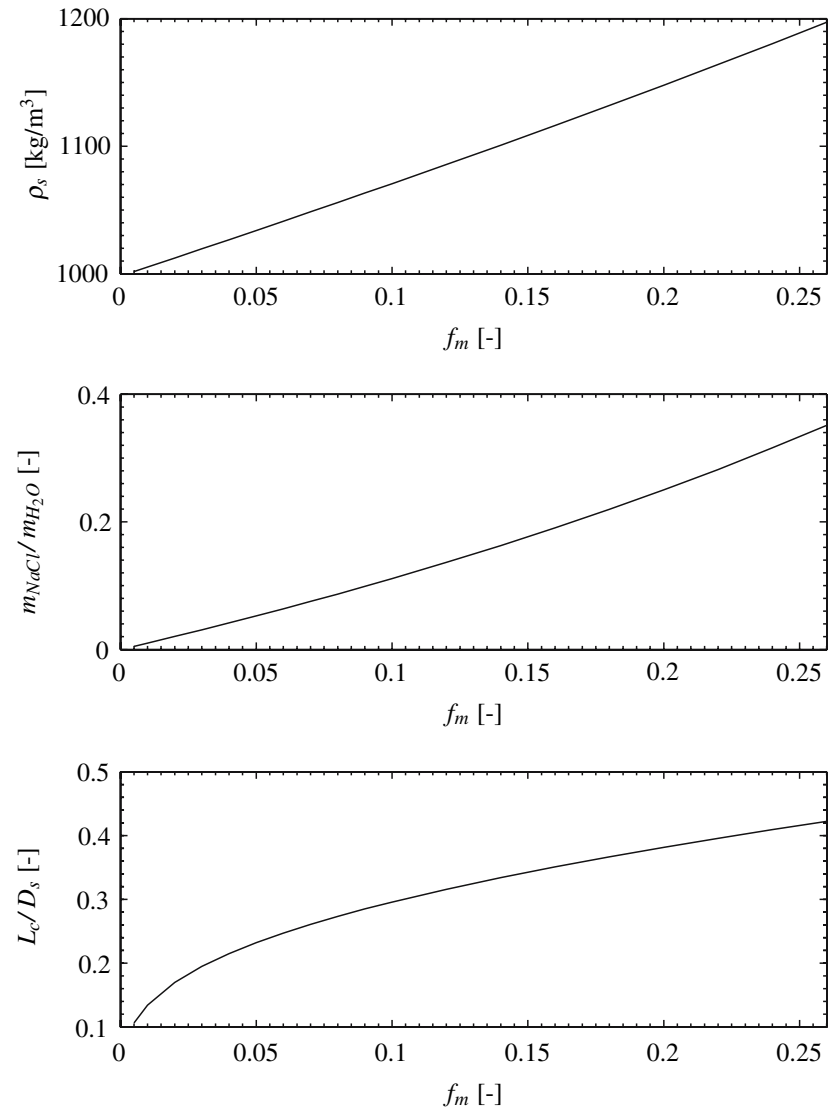

Fig. 3 Properties of sodium chloride aqueous solution and crystal edge length to droplet diameter ratio as a function of the mass of solute divided by total mass of solution $\frac{\pi}{6} D_{s}^{3} \rho_{s} f_{m}=L_{c}^{3} \rho_{c}$

$\frac{L_{c}}{D_{s}}=\left(\frac{\pi}{6} \frac{\rho_{s}}{\rho_{c}} f_{m}\right)^{1 / 3}$

$f_{m}=\frac{m_{\mathrm{NaCl}}}{m_{\mathrm{NaCl}}+m_{\mathrm{H}_{2} \mathrm{O}}}$

where $f_{m}$ denotes the mass of solute divided by total mass of solution and $\rho_{c}$ the crystal density which is $\rho_{c}=2,165 \mathrm{~kg} / \mathrm{m}^{3}$ at $25^{\circ} \mathrm{C}$ and 1 atm. The density of the solution $\rho_{s}$ is a function of $f_{m}$. The values at $20^{\circ} \mathrm{C}$ can be found in Lide (2004) and are given in Fig. 3 together with the computed length and mass ratios, Eqs. (2) and (3).

\subsection{Measured size distribution}

The particle size distribution for different values of $f_{m}$ was measured using a laser diffraction based particle size analyzer (Sympatec). In Fig. 4 the measured distributions are

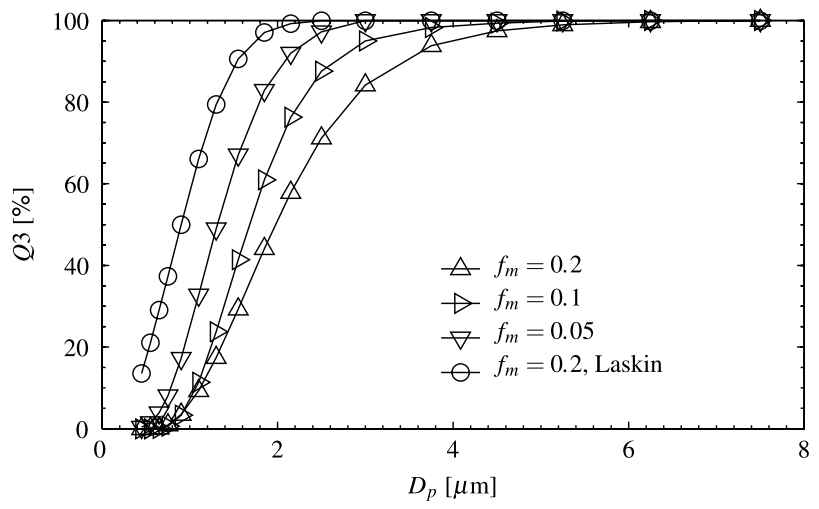

(a) Cumulative volumetric distribution function

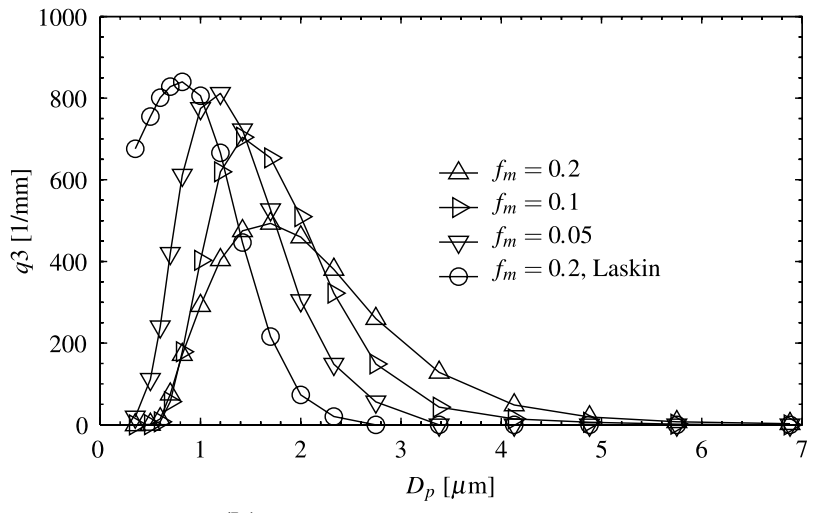

(b) Probability density function

Fig. 4 Measured cumulative volumetric distribution function, $Q 3$, and the corresponding probability density function, $q 3$, of the sodium chloride crystal particle size for different concentrations $f_{m}$ and produced by a ultrasonic atomizer (triangular symbols). In addition, one measurement using a Laskin nozzle is given (circle) 
Table 2 Median of the particle size and the measured and theoretical crystal size ratio for different concentrations assuming that the generated solution droplet size does not vary with $f_{m}$

\begin{tabular}{llllll}
\hline Generator & $\begin{array}{l}f_{m} \\
(-)\end{array}$ & $\begin{array}{c}\text { Median } \\
(\mu \mathrm{m})\end{array}$ & $\begin{array}{l}\text { Measured } \\
\frac{L_{c}^{f m}=0.05}{L_{c}^{f m}}\end{array}$ & $\begin{array}{l}\text { Theory } \\
\frac{L_{c}^{f m}=0.05}{L_{c}^{f m}}\end{array}$ & $\begin{array}{c}\text { Theory } \\
\frac{L_{c}}{D_{s}}\end{array}$ \\
\hline Ultrasound & 0.2 & 1.98 & 0.662 & 0.608 & 0.381 \\
& 0.1 & 1.68 & 0.780 & 0.785 & 0.296 \\
& 0.05 & 1.31 & 1 & 1 & 0.232 \\
Laskin & 0.2 & 0.90 & - & - & 0.381 \\
\hline
\end{tabular}

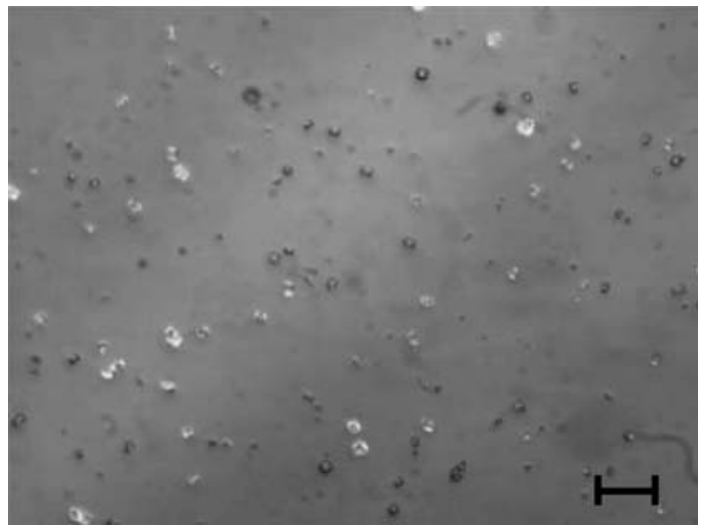

Fig. 5 Microscopy image of sodium chloride crystals produced with the ultrasonic atomizer. The indicated length scale represents $10 \mu \mathrm{m}$

given and the median values are listed in Table 2 . It can be seen that the crystals are smaller than $5 \mu \mathrm{m}$ and typical sizes range between 1 and $4 \mu \mathrm{m}$ for the ultrasonic atomizer operating in an almost saturated solution. Producing the crystals with a Laskin nozzle leads to smaller particles which could not be completely resolved with the available analyzer optics.

In order to check the theoretical approach for the particle size dependency on $f_{m}$, the measured and theoretically predicted particle size ratios for the different concentrations $f_{m}$ are also given in Table 2. The size of the generated solution droplet $D_{s}$ is assumed to be independent of $f_{m}$ for the theoretical prediction and Eq. 2 then leads to the listed values. Since measurements and theory agree well, the solution droplet size can be determined by Eq. 2 . The theoretical values for $L_{c} / D_{s}$ are also given in Table 2 .

A microscopy image of the sodium chloride crystals produced is given in Fig. 5. The depicted crystals are smaller than about $3 \mu \mathrm{m}$.

\section{Cut-off frequency and settling velocity}

In order to resolve flow fluctuations with LDA measurements, the seeding particles have to be able to follow the flow field and its variation in time. Especially measurements in gas flow are critical, as the density ratio of the particle material and the fluid becomes $\rho_{p} / \rho_{f} \gg 1$. In order to avoid significant inertia forces, the seeding particles have to be reasonable small. As discussed in Albrecht et al. (2003), the equation of particle motion of a spherical particle of diameter $D_{p}$ in a homogeneous velocity field neglecting particle/particle interactions is known as the Basset-Boussinesq-Oseen (BBO) equation. Considering periodical 1D velocity fluctuations of the flow field and very large density ratios $\rho_{p} / \rho_{f} \gg 1$, the equation can be solved for the cut-off frequency $f_{c}$ at which the particles still follow the velocity oscillations with a fraction $(1-s)$ of the amplitude.

$f_{c}=\frac{1}{\tau_{0}} \frac{1}{2 \pi} \sqrt{\frac{1}{(1-s)^{2}}-1}$

$\tau_{0}=\frac{\rho_{p} D_{p}^{2}}{18 \rho_{f} v}$

$s=\frac{u_{f}-u_{p}}{u_{f}}$

Here, $\tau_{0}$ is the characteristic time, $v$ the kinematic viscosity of the gas, $s$ the relative slip velocity and $u_{f}$ and $u_{p}$ are the fluid and the particle velocity, respectively. For a $1 \%$ slip, the critical frequency yields $f_{c}=0.0227 / \tau_{0}$.

Another characteristic number is the settling velocity $u_{s}$. A stationary, laminar flow is considered in which the gravitational force acting on the particle causes it to sink with time. The balance of drag force and gravitational force yields

$u_{s}=\frac{D_{p}^{2} \rho_{p}}{18 \rho_{f} v} g=\tau_{0} g$,

where $g$ is the gravitational acceleration.

The characteristic numbers for the measured median particle diameters are summarized in Table 3. Values for both 20 and $500^{\circ} \mathrm{C}$ are given under the assumption that the crystal density remains the same (cold crystal in hot gas). It can be seen that the variation of the gas density and gas kinematic viscosity with temperature have a large influence on the characteristic numbers. 
Table 3 Characteristic time, cut-off frequency, and settling velocity for the measured median particle diameters at both 20 and $500^{\circ} \mathrm{C}$

\begin{tabular}{lllll}
\hline $\begin{array}{c}\text { Particle diameter } \\
(\mu \mathrm{m})\end{array}$ & $\begin{array}{l}T \\
\left({ }^{\circ} \mathrm{C}\right)\end{array}$ & $\begin{array}{c}\tau_{0} \\
(\mu \mathrm{s})\end{array}$ & $\begin{array}{c}f_{c} \\
(\mathrm{~Hz})\end{array}$ & $\begin{array}{c}u_{s} \\
(\mathrm{~mm} / \mathrm{s})\end{array}$ \\
\hline 1.98 & 20 & 26 & 873 & 0.255 \\
1.98 & 500 & 13.3 & 1,708 & 0.130 \\
1.68 & 20 & 18.7 & 1,213 & 0.184 \\
1.68 & 500 & 9.57 & 2,372 & 0.094 \\
1.31 & 20 & 11.4 & 1,995 & 0.112 \\
1.31 & 500 & 5.82 & 3,902 & 0.057 \\
0.9 & 20 & 5.37 & 4,226 & 0.053 \\
0.9 & 500 & 2.75 & 8,267 & 0.027 \\
\hline
\end{tabular}

\section{Conclusion}

Cooking salt (sodium chloride, $\mathrm{NaCl}$ ) is being proposed as seeding material for hot gas flow up to $800^{\circ} \mathrm{C}$ when there is a risk of inhaling the seeded gas flow. Above this temperature, sodium chloride emits toxic fumes of chloride and sodium oxide and should not be used as a seeding material. The advantages of $\mathrm{NaCl}$ are the availability, the low material cost and the absence of a health risk for inhalation at the concentration levels used. A disadvantage is the corrosivity which has to be considered.

A simple technique was presented to produce small salt crystals of acceptable size using off-the-shelf products. A theoretical model for the influence of the $\mathrm{NaCl}$ concentration in the solution on the particle size was verified with experimental data. It was shown that the particle size can be controlled by the concentration of sodium chloride solution and therefore adjusted to the specific experimental requirements.

\section{References}

Albrecht HE, Borys M, Damaschke N, Tropea C (2003) Laser doppler and phase doppler measurement techniques. Springer, Heidelberg

Anderson SD, Spring J, Moore B, Rodwell LT, Spalding N, Gonda I, Chan K, Walsh A, Clark AR (1997) The effect of inhaling a dry powder of sodium chloride on the airways of asthmatic subjects. Eur Respir J 10:2465-2473

Durst F, Melling A, Whitelaw JH (1981) Principles and practice of laser-doppler anemometry. Academic, London

Green HL, Lane WR (1964) Particulate clouds: dust, smokes and mists. Spon, London

Lide DR (2004) CRC handbook of chemistry and physics. CRC, Boca Raton

Menter FR, Egorov Y, Rusch D (2006) Steady and unsteady flow modelling using the $k-\sqrt{k} L$ model. Fifth international symposium on turbulence, heat and mass transfer. Dubrovnik, Croatia, September 25-29

Rössler A, Skillas G, Pratsinis SE (2001) Nanopartikel-Materialien der Zukunft. Chemie in unserer Zeit 1:32-41

Rusch D (2007) Turbulence model validation for fire simulation by CFD and experimental investigation of a hot jet in crossflow. Ph.D. thesis, Diss. ETH No. 16966 